\title{
Optimality Conditions of Agricultural Production With Fixed Input Costs
}

\author{
Angel Ramon Sanchez Delgado \\ Universidade Federal Rural do Rio de Janeiro, Instituto de Ciências Exatas, Departamento de \\ Matemática, Brazil
}

Sergio Drumond Ventura

Universidade Federal Rural do Rio de Janeiro/ ICE/ Departamento de Matemática/ Seropédica/RJ/Brazil

Received: January 15, 2021

Accepted: February 7, 2021

Published: March 8, 2021

doi:10.5296/jas.v9i2.18389

URL: https://doi.org/10.5296/jas.v9i2.18389

\begin{abstract}
We present a computational procedure to maximize the production of a given agricultural crop with limited inputs (water-nitrogen), and where a fixed cost (or expense) of the inputs (general problem of agricultural production) is imposed. Theoretically the procedure is based on the Karush-Kuhn-Tucker optimality conditions and numerically was tested with three different scenarios defined in the literature, for the cultures: Lettuce, Oats, Onions and Melons. In each agricultural scenario considered, it was possible to verify that the procedure is a reliable alternative in making agribusiness economic decisions.
\end{abstract}

Keywords: response function, numerical scenario, Karush-Kuhn-Tucker condition

\section{Introduction}

Optimizing the production of agricultural crops, with limited inputs and spending on fixed inputs, has as a central tool in its mathematical modeling, the analytical quantification of productivity in response to the total inputs applied. Water and nitrogen are essential for the development of agricultural crops, and when they are correlated with the production obtained, there is the production function or water-nitrogen-culture response function.

The use of analytical production functions in the analysis of the results of agricultural experiments is widespread (Mousinho et al., 2003; Frizzone et al., 2005; Monteiro et al., 2006; Silva et al., 2008; Carvalho et al., 2009; Delgado et al., 2010 and Teodoro et al., 2013). Climatic variations, physical attributes related to the soil, the plant, and many other factors, 


\section{Macrothink

make it difficult to accurately predict crop yields. In practice, linear and/or quadratic regressions are generated to represent "good approximations" of the response or agricultural production functions.

We will assume that the inputs water and nitrogen are limited above and below. In addition, a limit on ceiling is imposed on the inputs used for the development of each culture. The resulting model presented is a nonlinear programming problem with linear constraints, considering that the objective is a quadratic function in two variables: water and nitrogen.

This work presents a computational model that directly maximizes the production of agricultural crops with limited inputs (water and nitrogen) and fixed spending on inputs. Some numerical tests with data known in the literature are performed, with the purpose of testing the effectiveness of the proposed procedure. We consider four annual agricultural crops (oat, onion and melon lettuce), representatives of the kingdom vegetables, fruits and cereals.

\section{Method}

Let $y(w, n)$ be the nonlinear analytical function of production or response of a given culture $\left(\mathrm{kg} \cdot \mathrm{ha} \mathrm{C}^{-1}\right)$ in relation to the water depth $w(\mathrm{~mm})$ and nitrogen dose $n$ ( $\left.\mathrm{kg}\right)$; $w_{l}, w_{u}, n_{l}, n_{u} \geq 0$, are the lower and upper limits of $w$ and $n$ respectively; $c_{w}$ the cost of a water depth $\left(R \$ . m m^{-1} \cdot h a^{-1}\right)$ and $c_{n}$ the cost of a dose of nitrogen $\left(R \$ . \mathrm{kg}^{-1} h a^{-1}\right)$.

Suppose that $c_{0}$ represents a fixed cost $\left(R \$ . h a^{-1}\right)$ intended exclusively to cover expenditure on water-nitrogen inputs. The problem that maximizes the production of a given agricultural crop with limited inputs and fixed spending on inputs, can be written mathematically as the problem of nonlinear programming with linear constraints:

$$
\text { maximize } y(w, n)
$$

subject to $r(w, n)=c_{w} w+c_{n} n=c_{0}$,

$$
\begin{aligned}
& w_{l} \leq w \leq w_{u}, \\
& n_{l} \leq n \leq n_{u} .
\end{aligned}
$$

In what follows, $y(w, n)=a w^{2}+b n^{2}+c w n+d w+e n+f$ (quadratic form in variables 
$w$ and $n)$; and where $a, b, c, d, e, f \in \mathbb{R}$ with $a<0$ and $4 a b-c^{2}>0$. Thus $y(w, n)$ is a strictly concave function and therefore reaches its maximum at the intersection of the two-dimensional box $\left[w_{l}, w_{u}\right] \times\left[n_{l}, n_{u}\right]$ and the plane $r(w, n)=c_{0}$. Note that we impose a limit on the spending on inputs $w$ e $n$, of $c_{0}$ - reais per hectare.

The problem $(\mathrm{P})$ can be written as:

$$
\begin{aligned}
& \operatorname{maximize} \quad y\left(w, n, z_{w^{v}}^{l} z_{w^{j}}^{u} z_{n^{\prime}}^{l} z_{n}^{u}\right)=a w^{2}+b n^{2}+c w n+d w+e n+f \\
& \text { subject to } c_{w} w+c_{n} n=c_{0} \text {, } \\
& w \quad-z_{w}^{l} \quad=w_{l}, \\
& w \quad+z_{w}^{u} \quad=w_{u}, \\
& n-z_{n}^{l} \quad=n_{l}, \\
& n \quad+z_{n}^{u} \quad=n_{u}, \\
& w_{s}, n, z_{w^{\prime}}^{l}, z_{w^{\prime}}^{u}, z_{n}^{l}, z_{n}^{u} \geq 0 .
\end{aligned}
$$

In matrix form the previous problem can be written as:

$\operatorname{maximize} \quad y\left(w, n, z_{w^{\prime}}^{l} z_{w^{3}}^{u} z_{n^{\prime}}^{l} z_{n}^{u}\right)=a w^{2}+b n^{2}+c w n+d w+e n+f$

subject to $A x=\rho$,

$x \geq 0$,

where 


$$
x=\left(\begin{array}{c}
w \\
n \\
z_{w}^{l} \\
z_{w}^{u} \\
z_{n}^{l} \\
z_{n}^{u}
\end{array}\right), \rho=\left(\begin{array}{c}
c_{0} \\
w_{l} \\
w_{u} \\
n_{l} \\
n_{u}
\end{array}\right) \text { and } A=\left(\begin{array}{cccccc}
c_{w} & c_{n} & 0 & 0 & 0 & 0 \\
1 & 0 & -1 & 0 & 0 & 0 \\
1 & 0 & 0 & 1 & 0 & 0 \\
0 & 1 & 0 & 0 & -1 & 0 \\
0 & 1 & 0 & 0 & 0 & 1
\end{array}\right)
$$

is a $5 \times 6$ full rank matrix Let the Lagrangean function associated with the problem above be defined by: $L(x, y, s)=y(x)+y^{T} h(x)-s^{T} x$, where: $y \in \mathbb{R}^{5}, h(x)=A x-\rho$, and $s \in \mathbb{R}^{6}$.

The variables $y$ and $s$ are the Lagrange multiplier vectors associated with the equality and inequality constraints respectively.

The Karush-Kuhn-Tucker optimality conditions (Wrigh, 1997; Roos et al., 1997) of problem (P) are given by:

$F(x, y, s)=\left(\begin{array}{c}\nabla_{x} L(x, y, s) \\ h(x) \\ X S e\end{array}\right)=0$,

where

$$
\begin{gathered}
\nabla_{x} L(x, y, s)=\nabla y(x)+\nabla h(x)^{T} y-s=\nabla y(x)+A^{T} y-s=0, \\
A x-\rho=0, \\
X S e=0, \\
x, s>0,
\end{gathered}
$$

and 


$$
\nabla y(x)=\left(\begin{array}{l}
\frac{\partial y}{\partial w} \\
\frac{\partial y}{\partial n} \\
\frac{\partial y}{\partial z_{w}^{l}} \\
\frac{\partial y}{\partial z_{w}^{u}} \\
\frac{\partial y}{\partial z_{n}^{L}} \\
\frac{\partial y}{\partial z_{n}^{u}}
\end{array}\right)=\left(\begin{array}{c}
2 a w+c n+d \\
2 b n+c w+e \\
0 \\
0 \\
0 \\
0
\end{array}\right) .
$$

Also, $X=\operatorname{diag}(x), s=\operatorname{diag}(s)$, and $e^{T}=(1,1,1,1,1,1)$. To solve problem $(\mathrm{P})$ using the primal-dual interior points method, we apply the Newton method to the disturbed KKT (barrier) conditions. It is given by:

$$
F_{\mu}(x, y, s)=\left(\begin{array}{c}
\nabla_{x} L(x, y, s) \\
h(x) \\
X S e-\mu e
\end{array}\right)=0
$$

or

$$
\begin{gathered}
\nabla y(x)+A^{T} y-s=0, \\
A x-\rho=0, \\
X S e-\mu e=0, \\
x, s>0 \text { and } y \in \mathbb{R}^{5},
\end{gathered}
$$

where $\mu>0$ is fixed and tends to zero.

The conceptual procedure for solving (1)-(3) works as follows: given a strictly positive initial solution and an initial parameter $\mu>0$, the Newton direction associated with the system (1)-(3) and a step length are calculated step in such a way that it allows iteratively to generate new strictly positive points. Then we make a decrease of $\mu$ and repeat the process until a stop criterion is satisfied. The Appendix contains the implemented computational procedure in 
pseudocode.

To computationally test the procedure, several numerical tests were performed using information known in the literature. Table 1 presents in an analytical way the response or production functions of the cultures: Lettuce (Silva et al., 2008), Oats (Frizzone et al., 1995), Onion (Baptestini, JCM, 1982) and Melon (Monteiro et al., 2006).

Table 1. Responses or production functions in quadratic forms in variables $w$ and $n$ for crops: Lettuce, Oats, Onions and Melons

\begin{tabular}{c|c}
\hline CULTURES & PRODUCTION FUNCTION $\left(\mathrm{kg} \cdot \mathrm{ha}^{-1}\right)$ \\
\hline Lettuce & $y(w, n)=-1.042 w^{2}-0.04563 n^{2}+0.1564 w n+388.1 w-6.02 n-12,490$ \\
\hline Oats & $y(w, n)=-5.6 \times 10^{-5} w^{2}-5.1 \times 10^{-5} n^{2}+3.6 \times 10^{-2} w+1.6 \times 10^{-2} n$ \\
\hline Onions & $y(w, n)=-2 \times 10^{-4} w^{2}-2 \times 10^{-4} n^{2}+3.28 \times 10^{-1} w+9.07 \times 10^{-2} n$ \\
\hline Melons & $y(w, n)=-0.05781 w^{2}-0.07612 n^{2}+70.77509 w+34.16737 n$ \\
\hline
\end{tabular}

According to the data provided by the bibliographic sources, for each crop (Lettuce, Oats, Onions and Melons) it is possible to determine lower and upper limit of the water depth; the lower ones between $100 \mathrm{~mm}$ and $600 \mathrm{~mm}$, and the upper ones between $400 \mathrm{~mm}$ and $600 \mathrm{~mm}$. For the nitrogen input, a ceiling of $300 \mathrm{~kg} \cdot \mathrm{ha}^{-1}$ was fixed, and considering that the most common in the literature for these cultures is a minimum dose of $75 \mathrm{~kg}_{\mathrm{ha}} \mathrm{ha}^{-1}$, three numerical tests defined by the two-dimensional boxes were performed: $[100,500] \times[0,300]$, $[100,400] \times[75,300]$ and $[100,600] \times[75,300]$. Table 2 shows the costs of a water depth $\left(c_{w}\right)$ and a dose of nitrogen $\left(c_{n}\right)$, for each agricultural crop. 
Table 2. Water cost $\left(c_{w}\right)$ and nitrogen cost $\left(c_{n}\right)$ for each crop considered

\begin{tabular}{c|c|c}
\hline \multirow{2}{*}{ CULTURES } & $\mathrm{c}_{\mathrm{w}}$ & $\mathrm{c}_{\mathrm{n}}$ \\
& $\left(\mathrm{R} \$ \mathrm{~mm}^{-1} \cdot \mathrm{ha}^{-1}\right)$ & $\left(\mathrm{R} \$ \mathrm{~kg}^{-1} \cdot \mathrm{ha}^{-1}\right)$ \\
\hline Lettuce & 0.44 & 2.09 \\
\hline Oats & 0.08 & 0.42 \\
\hline Onions & 0.025 & 1.20 \\
\hline Melons & 0.134 & 2.33 \\
\hline
\end{tabular}

\section{Results and Discussion}

Tables 3, 4, and 5 show the results obtained for each numerical test implemented. Table 3 informs that in the two-dimensional scenario $[100,500] \times[0,300]$ and for a fixed cost of inputs, water-nitrogen $\left(c_{0}\right)$ of $\mathrm{R} \$ 500$, Lettuce reaches its maximum production at the point $\left(w^{*}, n^{*}\right)=(200.278788,197.070494)$, Oats for a fixed cost of inputs of $\mathrm{R} \$ 100$, at the point $\left(w^{*}, n^{*}\right)=(324.788335,176.230793)$, Onions for a fixed cost of inputs of $\mathrm{R} \$ 200$, at point $\left(w^{*}, n^{*}\right)=(495.346309,156.346952)$ and Melon for a fixed input cost of $\mathrm{R} \$ 500$, at the point $\left(w^{*}, n^{*}\right)=(499.597687,185.860047)$. 
Table 3. Optimal solution $\left(w^{*}, n^{*}\right)$ and optimal value of the production $y\left(w^{*}, n^{*}\right)$ of $(\mathrm{P})$, in the two-dimensional box $[100,500] \times[0,300]$

\begin{tabular}{c|c|c|c|c}
\hline CULTURES & $w^{*}(\mathrm{~mm})$ & $n^{*}(\mathrm{~kg})$ & $y\left(w^{*}, n^{*}\right)\left(\mathrm{kg} \cdot \mathrm{ha}^{-1}\right)$ & $\mathrm{c}_{0}\left(\mathrm{R} \$ \cdot \mathrm{ha}^{-1}\right)$ \\
\hline Lettuce & 200.278788 & 197.070494 & $39,133.898980$ & 500 \\
\hline Oats & 324.788335 & 176.230793 & $7,020.853$ & 100 \\
\hline Onions & 495.346309 & 156.346952 & 122.691791 & 200 \\
\hline Melons & 499.597687 & 185.860047 & $24,650.337159$ & 500 \\
\hline
\end{tabular}

It is possible to show graphically the trajectory of points generated by the implemented procedure, converging to the optimal solution of the problem, for each culture considered. Figure 1, for example, shows for the Oats culture, the sequence of interior points in the two-dimensional box $[100,500] \times[0,300]$ generated by the implemented procedure and converging to the optimal solution $(324.788335,176.230793)$. Note that this optimal solution satisfies the plane equation: $r(w, n)=0.08 w+0.42 n=100$.

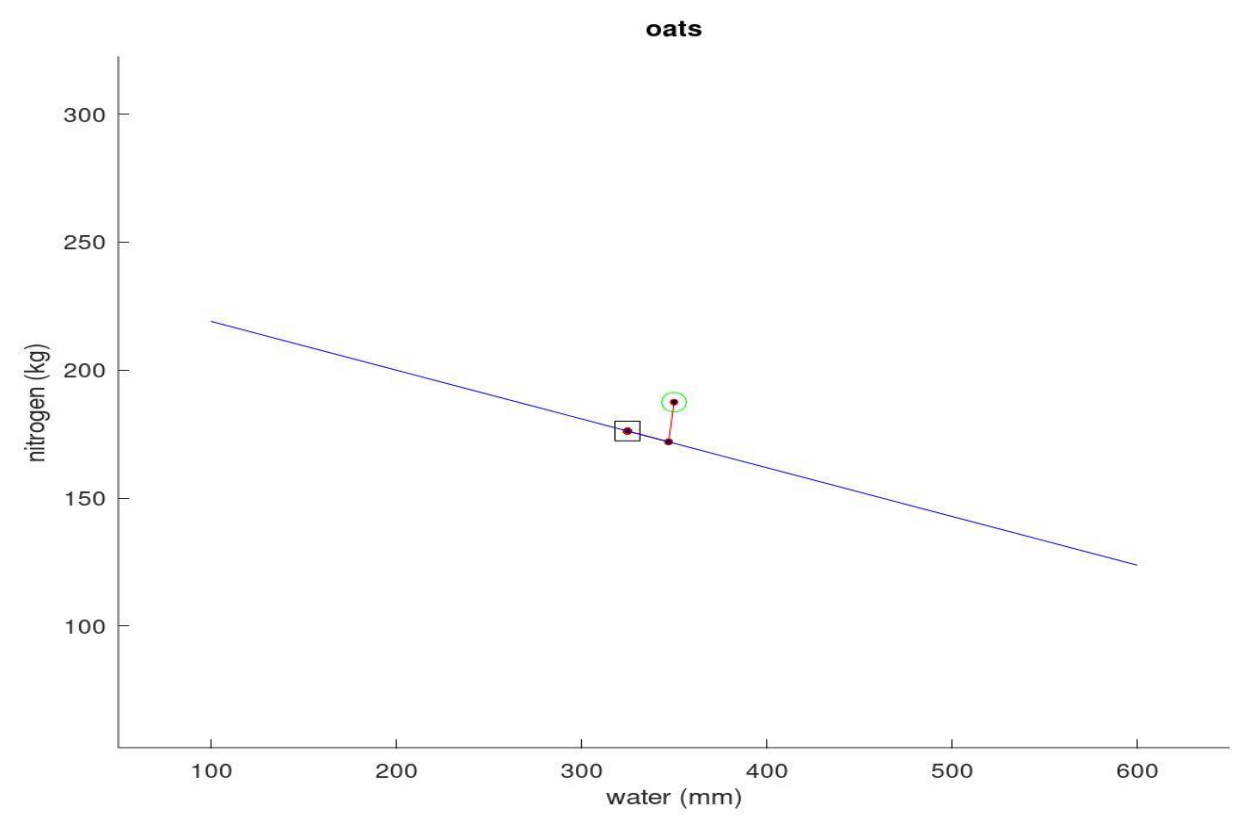


Figure 1. sequence of points generated by the procedure in the two-dimensional box $[100,500] \times[0,300]$ for Oats, converging to the point $(324.788335,176.230793)$

Table 4 shows the results obtained in the two-dimensional box $[100,400] \times[75,300]$, informing that in this scenario and for a fixed input cost of $\mathrm{R} \$ 500$, Lettuce reaches its maximum production at the point $\left(w^{*}, n^{*}\right)=(200.278788,197.070494)$, Oats for a fixed cost of inputs of $\mathrm{R} \$ 100$, at the point $\left(w^{*}, n^{*}\right)=(324.788335,176.230793)$, Onions for a fixed cost of inputs of $\mathrm{R} \$ 200$, at point $\left(w^{*}, n^{*}\right)=(397.685996,158.381542)$ and Melons for a fixed cost of inputs of $\mathrm{R} \$ 500$, at point $\left(w^{*}, n^{*}\right)=(399.364956,191.624505)$.

Table 4. Optimal solution $\left(w^{*}, n^{*}\right)$ and optimal value of the production $y\left(w^{*}, n^{*}\right)$ of $(\mathrm{P})$, in the two-dimensional box $[100,400] \times[75,300]$

\begin{tabular}{c|l|c|c|c}
\hline CULTURES & $w^{*}(\mathrm{~mm})$ & $n^{*}(\mathrm{~kg})$ & $y\left(w^{*}, n^{*}\right)\left(\mathrm{kg} \cdot \mathrm{ha} \mathrm{a}^{-1}\right)$ & $\mathrm{c}_{0}\left(\mathrm{R} \$ \cdot \mathrm{ha}^{-1}\right)$ \\
\hline Lettuce & 200.278788 & 197.070494 & $39,133.898980$ & 500 \\
\hline Oats & 324.788335 & 176.230793 & $7,020.853$ & 100 \\
\hline Onions & 397.685996 & 158.381542 & 108.158440 & 200 \\
\hline Melons & 399.364956 & 191.624505 & $22,796.652408$ & 500 \\
\hline
\end{tabular}

Figure 2 shows for the onion crop, the sequence of interior points in the two-dimensional box $[100,400] \times[75,300]$ generated by the implemented procedure and converging to the optimal solution $(397.685996,158.381542)$. Note that this optimal solution satisfies the plane equation: $r(w, n)=0.025 w+1.20 n=200$. 


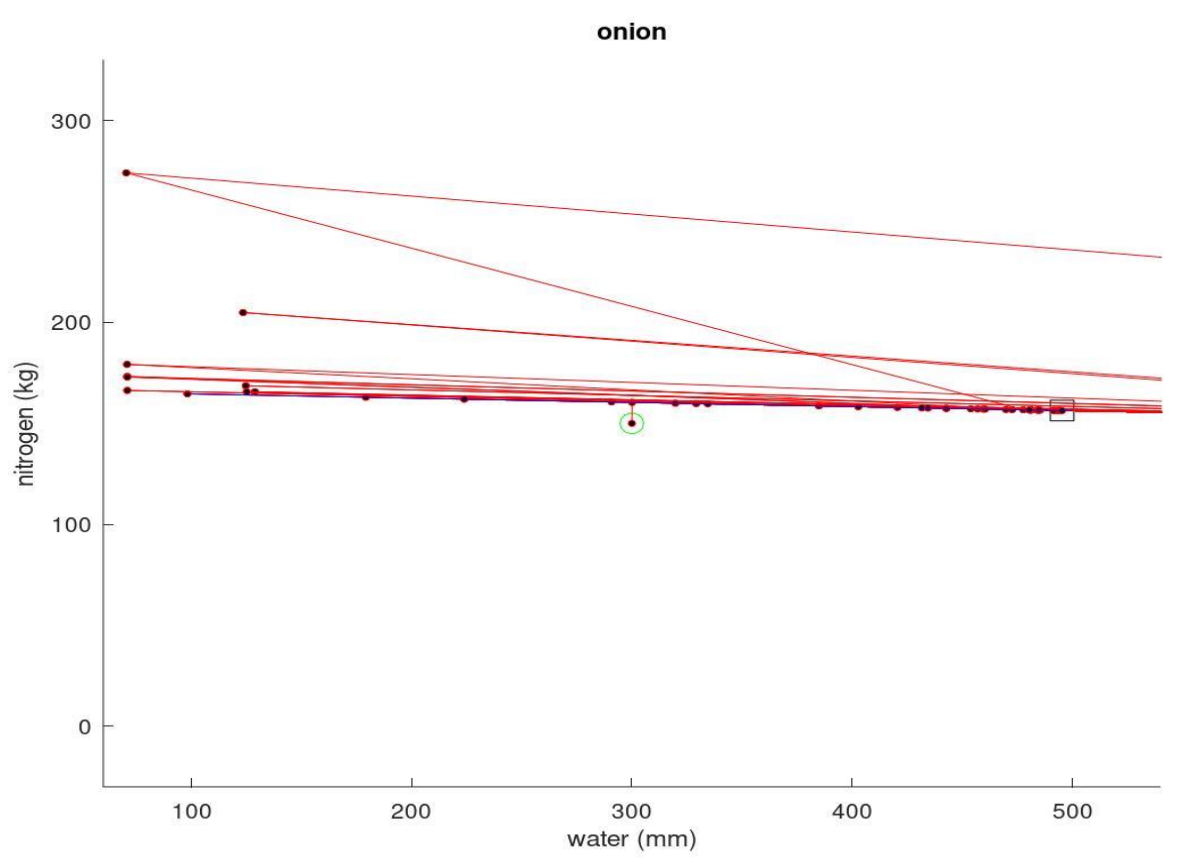

Figure 2. Sequence of points generated by the procedure in the two-dimensional box $[100,400] \times[75,300]$ for Onion, converging to the point $(360.198429,159.162527)$

Comparing the results obtained in the first scenario $[100,500] \times[0,300]$ (Table 1$)$ with those obtained in the second scenario $[100,400] \times[75,300]$ (Table 2), we can observe that the lettuce culture, for the same fixed cost $c_{0}=500 R \$ . h a^{-1}$, presented equal results in relation to water depth, nitrogen dose and productivity. The same happened with the culture of Oats, for a fixed cost of $c_{0}=500 R \$ \cdot h a^{-1}$.

As for the onion crop, for the same fixed cost $c_{0}=200 R \$ . h a^{-1}$, it can be noted that in the second scenario (Table 2), there was a reduction of $97.66 \mathrm{~mm}$ in relation to the water depth, a slight increase of $2.03 \mathrm{~kg}$ in relation to the nitrogen dose, and a drop in productivity of $14.53 \mathrm{~kg} \cdot \mathrm{ha} \mathrm{a}^{-1}$. In the case of Melon, for the same fixed cost $c_{0}=500 \mathrm{R} \$ \mathrm{ha} \mathrm{a}^{-1}$, we obtained a drop of $100.23 \mathrm{~mm}$ in relation to the water depth, an increase of $5.76 \mathrm{~kg}$ in relation to the nitrogen dose, and a significant drop in productivity of $1,853.68 \mathrm{~kg} \cdot \mathrm{ha}^{-1}$. 
Finally, Table 5 presents the results obtained for the third scenario performed in the two-dimensional box $[100,600] \times[75,300]$.

Table 5. Optimal solution $\left(w^{*}, n^{*}\right)$ and optimal value of the production $y\left(w^{*}, n^{*}\right)$ of $(\mathrm{P})$, in the two-dimensional box $[100,600] \times[75,300]$.

\begin{tabular}{c|l|l|l|c}
\hline CULTURES & $w^{*}(\mathrm{~mm})$ & $n^{*}(\mathrm{~kg})$ & $y\left(w^{*}, n^{*}\right)\left(\mathrm{kg} \mathrm{ha}^{-1}\right)$ & $\mathrm{c}_{0}\left(\mathrm{R} \$ \cdot \mathrm{ha}^{-1}\right)$ \\
\hline Lettuce & 200.278788 & 197.070494 & $39,133.898980$ & 500 \\
\hline Oats & 324.788335 & 176.230793 & $7,020.853$ & 100 \\
\hline Onions & 594.522030 & 154.280791 & 133.544692 & 200 \\
\hline Melons & 599.97332 & 180.08737 & $25,337.52122$ & 500 \\
\hline
\end{tabular}

Note that the Lettuce and Oats crops again remain invariant in relation to the first two scenarios. For Onion there was an increase in relation to the water depth of around $196.84 \mathrm{~mm}$, a reduction in the nitrogen dose of $2.03 \mathrm{~kg}$ and a decrease in productivity of $25,39 \mathrm{~kg} \cdot \mathrm{ha}^{-1}$. Finally, in relation to Melon, and for a fixed cost of inputs of $\mathrm{R} \$ 500$, we achieved the highest productivity $\left(25,337.52122 \mathrm{~kg} \cdot \mathrm{ha}^{-1}\right)$ and the lowest dose of nitrogen (180.08737 $\left.\mathrm{kg} \cdot \mathrm{ha}^{-1}\right)$ among the three numerical scenarios considered.

Figure 3 shows for the Melon culture, the sequence of interior points in the two-dimensional box $[100,600] \times[75,300]$ generated by the implemented procedure and converging to the optimal solution $(599.97332,180.08737)$. Note that this optimal solution satisfies the plane equation: $r(w, n)=0.134 w+2.33 n=500$. 


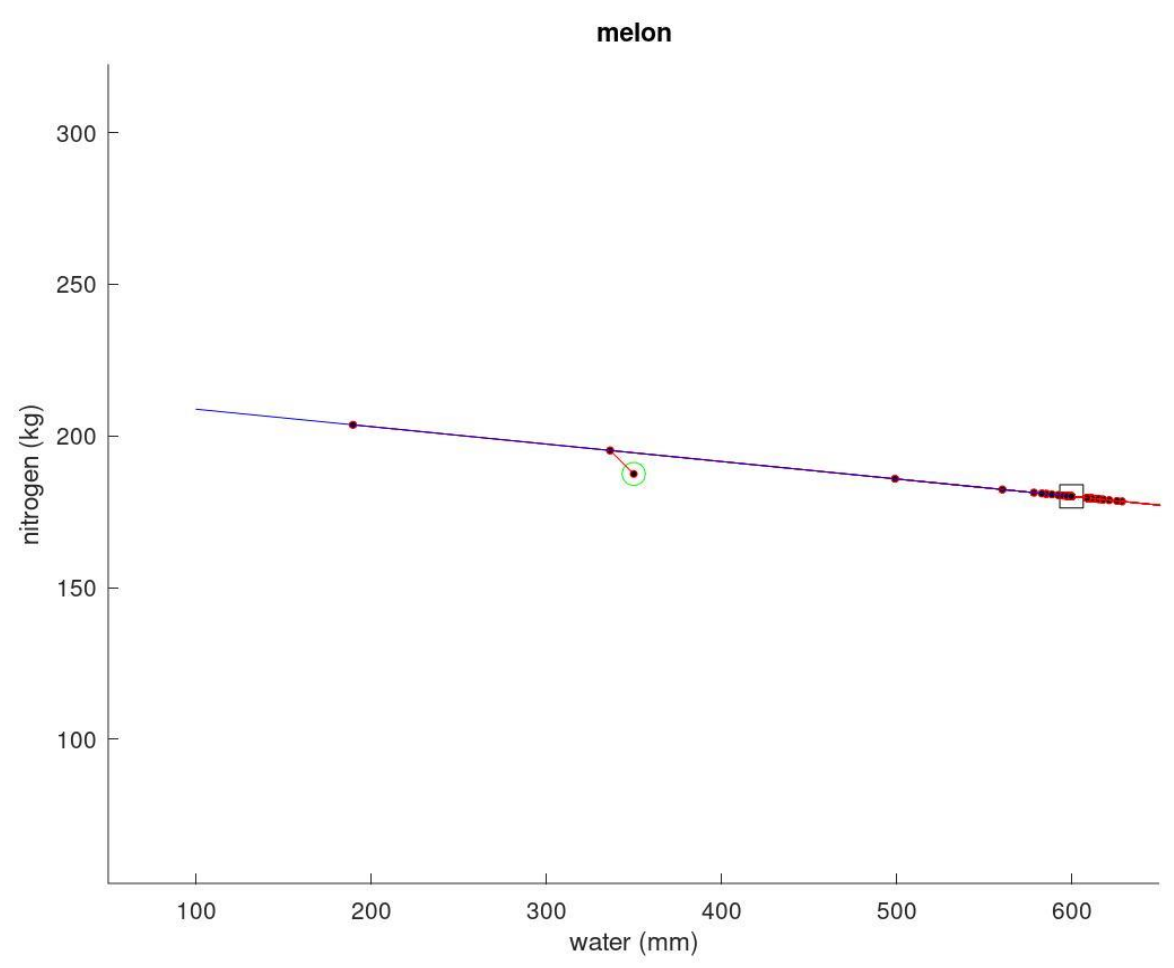

Figure 3. sequence of points generated by the procedure in the two-dimensional box

$[100,600] \times[75,300]$ for the Melon, converging to the point $(599.97332,180.08737)$

It is important to emphasize that the proper management of the water layer $(w)$ is fundamental, considering that the agricultural sector is the largest consumer of water, and that water resources are essential and strategic in the development of agriculture. Also, considering that currently the costs of nitrogen fertilization, specifically nitrogen $(n)$, are increasingly variable, and that the demand in Brazil grows every day, it is necessary to respect the environmental and soil preservation issues, as a fundamental part for sustainable agriculture. In relation to fixed costs $\left(c_{0}\right)$, we will have a fixed amount in $\mathrm{R} \$$, for each crop and each scenario considered.

\section{Conclusions}

- We present a computational procedure based on the conditions of optimality Karush-Kuhn-Tucker, to maximize the production of a certain agricultural culture with limited inputs (water-nitrogen), and a fixed cost (or expense) of the inputs.

- For each agricultural scenario considered, we were able to confirm that all the optimal solutions of $(\mathrm{P})$ generated by the procedure, satisfy the imposed restrictions. 
- In the three numerical scenarios presented, Lettuce and Oats were the only agricultural crops considered to remain invariant in relation to the water depth, nitrogen dose and productivity.

- Finally, when making agricultural production decisions (agribusiness), it is important to deal with problems where it is desired to maximize the production of a given agricultural crop with limited inputs (water-nitrogen), and where there must be a fixed cost for the input expenses.

\section{References}

Baptestini, J. C. M. (2013). Produção de cebola submetida a diferentes lâminas de água e doses de nitrogênio com adubação molibdica. Tese de Doutorado, UFV (Brasil), 102 p.

Carvalho, D. F., Delgado, A. R. S., Oliveira, R. F., Silva, W. A., \& Forte, V. L. (2009). Maximização da produção e da receita agrícola com limitações de água e nitrogênio utilizando método de pontos interiores. Engenharia Agrícola, Jaboticabal, 29(2), 321-327. https://doi.org/10.1590/S0100-69162009000200015

Delgado, A. R. S., Duarte, S. W., Limas, N. V., \& Fonseca, D. (2010). Modelagem matemática para otimização da produção e renda de melão e melancia em função de lâminas de água e doses de nitrogênio. Irriga, Botucatu, 15(1), p.1-9. https://doi.org/10.15809/irriga.2010v15n1p01

Frizzone, J. A., Teodoro, R. E. F., Pereira A. S., \& Botrel, T. A. (1995). Lâmina de água e doses de nitrogênio na produção de aveia (Avena sativa L.) para forragem. Scientia Agricola, Piracicaba, 52(3), 578-586. https://doi.org/10.1590/S0103-90161995000300027

Frizzone, J. A., \& Andrade Júnior, A. S. (2005). Planejamento de irrigação: análise de decisão de investimento. Brasília: Embrapa Informação Tecnológica. 626 p.

Monteiro, R. O. C., Colares, D. S., Costa T. R. N., Leão, M. C. S., \& de Aguiar, J. V. (2006). Função de resposta do meloeiro a diferentes lâminas de irrigação e doses de nitrogênio. Horticultura Brasileira, Vitória da Conquista, 24(4), 455-459. https://doi.org/10.1590/S0102-05362006000400012

Mousinho, F. E. P., Costa, R. N. T., Souza, F. D., \& Gomes Filho, R. R. (2003). Função de resposta da melancia à aplicação de água e nitrogênio para as condições Edafoclimáticas de $\begin{array}{lllll}\text { Fortaleza, } & \text { CE. } & \text { Irriga, } & \text { Botucatu, } & \text { 8(3), }\end{array}$ https://doi.org/10.15809/irriga.2003v8n3p264-272

Silva, P. A. M., Pereira, G.M., Reis, R. P., Lima, L. A., \& Taveira, J. H. S. (2008). Função de resposta da alface americana aos níveis de água e adubação nitrogenada. Ciência Agrotécnica, Lavras, 32(4), 1266-1271. https://doi.org/10.1590/S1413-70542008000400035

Roos, C., Terlaky, T., \& Vial, J. P. H. (1997). Theory and Algorithms for Linear Optimization. John Wiley \& Sons Ltda, England.

Teodoro, I. T., Neto, J. D. D., Souza, J. L., Lyra, G. B., Brito, K. S., Sá, L.A, ... Sarmento, P. 


\section{Macrothink}

Journal of Agricultural Studies

ISSN 2166-0379 2021, Vol. 9, No. 2

L. V. S. (2013). Isoquantas de Produtividade da Cana-de-açúcar em Função de Níveis de Irrigação e Adubação Nitrogenada. Irriga, Botucatu, $18(3), \quad 387$. https://doi.org/10.15809/irriga.2013v18n3p387

Wright, S. J. (1997). Primal-Dual Interior Point Methods, SIAM Journal, pp 289-304, 1997. https://doi.org/10.1137/1.9781611971453

\section{Appendix}

The system (1)-(2)-(3) can be written as:

$$
\begin{aligned}
& 2 a w+c n+c_{w} y_{1}+y_{2}+y_{3}-s_{1}=-d \\
& 2 b n+c w+c_{n} y_{1}+y_{4}+y_{5}-s_{2}=-e \\
& -y_{2}-s_{3}=0 \\
& y_{3}-s_{4}=0 \\
& -y_{4}-s_{5}=0 \\
& y_{5}-s_{6}=0 \\
& c_{w} w+c_{n} n=c_{0} \\
& w-z_{w}^{l}=w_{l} \\
& w+z_{w}^{u}=w_{u} \\
& n-z_{n}^{l}=n_{l} \\
& n+z_{n}^{u}=n_{u} \\
& w s_{1}=\mu \\
& n s_{2}=\mu \\
& z_{w}^{l} s_{3}=\mu
\end{aligned}
$$


$z_{w}^{u} s_{4}=\mu$

$z_{n}^{l} s_{5}=\mu$

$z_{n}^{u} s_{6}=\mu$

$w, n, y_{1}, y_{2}, y_{3}, y_{4}, y_{5}, s_{1}, s_{2}, s_{3}, s_{4}, s_{5}, s_{6}, z_{w^{3}}^{l} z_{w^{\prime}}^{u}, z_{n}^{l}, z_{n}^{u} \geq 0$

The previous system of equations is nonlinear with 17 equations and 17 variables, and can be solved using Newton's method.

NEWTON DIRECTION:

We search for a direction:

$\left(\Delta w, \Delta n, \Delta y_{1}, \Delta y_{2}, \Delta y_{3}, \Delta y_{4}, \Delta y_{5}, \Delta s_{1}, \Delta s_{2}, \Delta s_{3}, \Delta s_{4}, \Delta s_{5}, \Delta s_{6}, \Delta z_{w^{3}}^{l} \Delta z_{w^{3}}^{u} \Delta z_{n}^{l}, \Delta z_{n}^{u}\right)$

such that:

$2 a \Delta w+c \Delta n+c_{w} \Delta y_{1}+\Delta y_{2}+\Delta y_{3}-\Delta s_{1}=-d-2 a w-c n-c_{w} y_{1}-y_{2}-y_{3}+s_{1}$

$2 b \Delta n+c \Delta w+c_{n} \Delta y_{1}+\Delta y_{4}+\Delta y_{5}-\Delta s_{2}=-e-2 b n-c w-c_{n} y_{1}-y_{4}-y_{5}+s_{2}$

$-\Delta y_{2}-\Delta s_{3}=y_{2}+s_{3}$

$\Delta y_{3}-\Delta s_{4}=-y_{3}+s_{4}$

$-\Delta y_{4}-\Delta s_{5}=y_{4}+s_{5}$

$\Delta y_{5}-\Delta s_{6}=-y_{5}+s_{6}$

$c_{w} \Delta w+c_{n} \Delta n=c_{0-} c_{w} w-c_{n} n$

$\Delta w-\Delta z_{w}^{l}=w_{l}-w+z_{w}^{l}$

$\Delta w+\Delta z_{w}^{u}=w_{u}-w-z_{w}^{u}$

$\Delta n-\Delta z_{n}^{l}=n_{l}-n+z_{n}^{l}$ 


$$
\begin{aligned}
& \Delta n+\Delta z_{n}^{u}=n_{u}-n-z_{n}^{u} \\
& w \Delta s_{1}+s_{1} \Delta w=\mu-w s_{1} \\
& n \Delta s_{2}+s_{2} \Delta n=\mu-n s_{2} \\
& z_{w}^{l} \Delta s_{3}+s_{3} \Delta z_{w}^{l}=\mu-z_{w}^{l} s_{3} \\
& z_{w}^{u} \Delta s_{4}+s_{4} \Delta z_{w}^{u}=\mu-z_{w}^{u} s_{4} \\
& z_{n}^{l} \Delta s_{5}+s_{5} \Delta z_{n}^{l}=\mu-z_{n}^{l} s_{5} \\
& z_{n}^{u} \Delta s_{6}+s_{6} \Delta z_{n}^{u}=\mu-z_{n}^{u} s_{6} .
\end{aligned}
$$

Define:

$$
\begin{aligned}
& \theta_{1}=-d-2 a w-c n-c_{w} y_{1}-y_{2}-y_{3}+s_{1} \\
& \theta_{2}=-e-2 b n-c w-c_{n} y_{1}-y_{4}-y_{5}+s_{2} \\
& \theta_{3}=y_{2}+s_{3} \\
& \theta_{4}=-y_{3}+s_{4} \\
& \theta_{5}=y_{4}+s_{5} \\
& \theta_{6}=-y_{5}+s_{6} \\
& \theta_{7}=c_{0}-c_{w} w-c_{n} n \\
& \theta_{8}=w_{l}-w+z_{w}^{l} \\
& \theta_{9}=w_{u}-w-z_{w}^{u} \\
& \theta_{10}=n_{l}-n+z_{n}^{l}
\end{aligned}
$$




$$
\begin{aligned}
& \theta_{11}=n_{u}-n-z_{n}^{u} \\
& \theta_{12}=\mu-w s_{1} \\
& \theta_{13}=\mu-n s_{2} \\
& \theta_{14}=\mu-z_{w}^{l} s_{3} \\
& \theta_{15}=\mu-z_{w}^{u} s_{4} \\
& \theta_{16}=\mu-z_{n}^{l} s_{5} \\
& \theta_{17}=\mu-z_{n}^{u} s_{6} .
\end{aligned}
$$

So, the linear system for determining Newton's direction is given by:

$$
\begin{aligned}
& 2 a \Delta w+c \Delta n+c_{w} \Delta y_{1}+\Delta y_{2}+\Delta y_{3}-\Delta s_{1}=\theta_{1} \\
& 2 b \Delta n+c \Delta w+c_{n} \Delta y_{1}+\Delta y_{4}+\Delta y_{5}-\Delta s_{2}=\theta_{2} \\
& -\Delta y_{2}-\Delta s_{3}=\theta_{3}
\end{aligned}
$$

$$
\Delta y_{3}-\Delta s_{4}=\theta_{4}
$$$$
-\Delta y_{4}-\Delta s_{5}=\theta_{5}
$$

$$
\begin{aligned}
& \Delta y_{5}-\Delta s_{6}=\theta_{6} \\
& c_{w} \Delta w+c_{n} \Delta n=\theta_{7} \\
& \Delta w-\Delta z_{w}^{l}=\theta_{8}
\end{aligned}
$$


$\Delta w+\Delta z_{w}^{u}=\theta_{9}$

$\Delta n-\Delta z_{n}^{l}=\theta_{10}$

$\Delta n+\Delta z_{n}^{u}=\theta_{11}$

$w \Delta s_{1}+s_{1} \Delta w=\theta_{12}$

$n \Delta s_{2}+s_{2} \Delta n=\theta_{13}$

$z_{w}^{l} \Delta s_{3}+s_{3} \Delta z_{w}^{l}=\theta_{14}$

$z_{w}^{u} \Delta s_{4}+s_{4} \Delta z_{w}^{u}=\theta_{15}$

$z_{n}^{l} \Delta s_{5}+s_{5} \Delta z_{n}^{l}=\theta_{16}$

$z_{n}^{u} \Delta s_{6}+s_{6} \Delta z_{n}^{u}=\theta_{17}$.

\section{PROCEDURE}

DATA: $\quad a, b, c, d, e, f \in \mathbb{R} \quad$ with $\quad a<0$ and $4 a b-c^{2}>0 . \quad w_{l}, w_{u}, n_{l_{n}} n_{u} \geq 0 \quad$ with $w_{u} \geq w_{l} \quad, \quad n_{u} \geq n_{l} \quad, \quad c_{0}, c_{w^{v}}, c_{n} \in \mathbb{R}_{+} \quad ; \quad w, n, s_{1}, s_{2}, s_{3}, s_{4}, s_{5}, s_{6}, z_{w^{p}}^{l} z_{w^{p}}^{u} z_{n}^{l}, z_{n}^{u}>0 ;$ $y_{1}, y_{2}, y_{3}, y_{4}, y_{5} \in \mathbb{R} ; \tau, \alpha \in(0,1), \varepsilon_{i} \in(0,1)$ for $i=1,2, \ldots, 11$;

WHILE optimum was not found DO

LET $\quad \sigma_{1}=\frac{\left\|-2 a w-c n-c_{1} y_{1}-y_{2}-y_{8}+s_{1}\right\|}{\|d\|+1}, \quad \sigma_{2}=\frac{\left\|2 b n+c w+c_{n} y_{1}+y_{4}+y_{5}-s_{2}\right\|}{\|\boxminus\|+1}$,

$$
\sigma_{3}=\left|y_{2}+s_{3}\right|, \quad \sigma_{4}=\left|y_{3}-s_{4}\right|, \quad \sigma_{5}=\left|-y_{4}-s_{5}\right|, \quad \sigma_{6}=\left|y_{5}-s_{6}\right|,
$$




$$
\begin{array}{ll}
\sigma_{7}=\frac{\left|c_{w} w+c_{n} n\right|}{c_{0+1}}, & \sigma_{8}=\frac{\left|w-z_{w}^{I}\right|}{w_{l}+1}, \quad \sigma_{9}=\frac{\left|w+z_{w}^{u}\right|}{w_{u}+1}, \quad \sigma_{10}=\frac{\left|n-z_{n}^{\mathbb{I}}\right|}{n_{l}+1}, \\
\sigma_{11}=\frac{\| n+z_{n}^{u} \mid}{n_{u}+1}, & \mu=\frac{\tau}{6}\left(w s_{1}+n s_{2}+z_{w}^{l} s_{3}+z_{w}^{u} s_{4}+z_{n}^{l} s_{5}+z_{n}^{u} s_{6}\right) ;
\end{array}
$$

IF $\quad \mu<10^{-4}$ and $\sigma_{\bar{i}}<\varepsilon_{i}$, for $i=1,2, \ldots, 11$ THEN

$$
\text { STOP, optimum was found; }
$$

\section{END IF}

FOR $j=1,2, \ldots, 17$

\section{EVALUATE $\theta_{i}$;}

DETERMINE THE NEWTON DIRECTION:

FIND

$\left(\Delta w, \Delta n, \Delta y_{1}, \Delta y_{2}, \Delta y_{3}, \Delta y_{4}, \Delta y_{5}, \Delta s_{1}, \Delta s_{2}, \Delta s_{3}, \Delta s_{4}, \Delta s_{5}, \Delta s_{6}, \Delta z_{w^{3}}^{l} \Delta z_{w^{3}}^{u} \Delta z_{n}^{l}, \Delta z_{n}^{u}\right)$

satisfying (4)-(20);

DETERMINE STEP LENGTH:

LET

$$
\begin{aligned}
& \beta_{p}^{w}=\frac{1}{\max \left\{1_{n}-\frac{\Delta w}{\alpha w}\right\}} ; \quad \beta_{p}^{n}=\frac{1}{\max \left\{1_{1}-\frac{\Delta n}{\alpha n}\right\}} ; \\
& \beta_{p}^{l w}=\frac{1}{\max \left\{1_{0}-\frac{\Delta z_{W}^{l}}{\alpha z_{W}^{l}}\right\}} ; \quad \beta_{p}^{u w}=\frac{1}{\max \left\{1_{0}-\frac{\Delta z_{W}^{u}}{\alpha z_{W}^{u}}\right\}} ; \\
& \beta_{p}^{l n}=\frac{1}{\max \left\{1_{n}-\frac{\Delta z_{n}^{l}}{\omega z_{n}^{l}}\right\}} ; \quad \beta_{p}^{u n}=\frac{1}{\max \left\{1_{2}-\frac{\Delta z_{n}^{n}}{\alpha z_{n}^{n}}\right\}} ;
\end{aligned}
$$

FOR $j=1,2, \ldots, 5$

LET $\beta_{d}^{y j}=\frac{1}{\max \left[1_{i}-\Delta y_{j} / y_{j}\right]}$ 
FOR $j=1,2, \ldots, 6$

LET $\beta_{d}^{s j}=\frac{1}{\max \left\{1_{i}-\Delta s_{j} / s_{j}\right\}}$

UPDATE THE SOLUTION:

LET $\quad w=w+\beta_{p}^{w} \Delta w ; \quad n=n+\beta_{p}^{n} \Delta w ;$

FOR $j=1,2, \ldots, 5$

LET $y_{j}=y_{j}+\beta_{d}^{y j} \Delta y_{j}$;

FOR $j=1,2, \ldots, 6$

LET $s_{j}=s_{j}+\beta_{d}^{s j} \Delta s_{j}$

LET $\quad z_{w}^{l}=z_{w}^{l}+\beta_{p}^{l w} \Delta z_{w}^{l} ; \quad z_{w}^{u}=z_{w}^{u}+\beta_{p}^{u w} \Delta z_{w}^{u} ;$

$z_{n}^{l}=z_{n}^{l}+\beta_{p}^{l n} \Delta z_{n}^{l} ; \quad z_{n}^{u}=z_{n}^{u}+\beta_{p}^{u n} \Delta z_{n}^{u}$.

\section{END WHILE}

\section{Copyright Disclaimer}

Copyright for this article is retained by the author(s), with first publication rights granted to the journal.

This is an open-access article distributed under the terms and conditions of the Creative Commons Attribution license (http://creativecommons.org/licenses/by/4.0/). 